FROM THE COVER

\title{
Microsatellite genotyping reveals end-Pleistocene decline in mammoth autosomal genetic variation
}

\author{
VERONICA NYSTRÖM,*†‡ JOANNE HUMPHREY,§ PONTUS SKOGLUND, NIALL J. \\ MCKEOWN, $\S^{* *}$ SERGEY VARTANYAN,†+ PAUL W. SHAW, §** KERSTIN LIDÉN,† MATTIAS

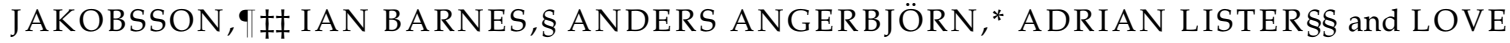 \\ DALÉN‡§ \\ *Department of Zoology, Stockholm University, S-106 91 Stockholm, Sweden, +Archaeological Research Laboratory, Stockholm \\ University, S-106 91 Stockholm, Sweden, ‡Department of Molecular Systematics, Swedish Museum of Natural History, S-104 \\ 05 Stockholm, Sweden, §School of Biological Sciences, Royal Holloway, University of London, Egham, Surrey TW20 0EX, UK, \\ -Department of Evolutionary Biology, Evolutionary Biology Centre, Uppsala University, S-752 36 Uppsala, Sweden, **Institute \\ of Biological, Environmental and Rural Sciences (IBERS), Aberystwyth University, Penglais, Aberystwyth SY23 3DA, UK, \\ +†Northeast Interdisciplinary Research Institute, Far East Branch, Russian Academy of Sciences, 16 Portovaya St., Magadan \\ 685000, Russia, 抽ience for Life Laboratory, Uppsala University, S-751 23 Uppsala, Sweden, §§Department of Palaeontology, \\ Natural History Museum, Cromwell Road, London SW7 5BD, UK
}

\begin{abstract}
The last glaciation was a dynamic period with strong impact on the demography of many species and populations. In recent years, mitochondrial DNA sequences retrieved from radiocarbon-dated remains have provided novel insights into the history of Late Pleistocene populations. However, genotyping of loci from the nuclear genome may provide enhanced resolution of population-level changes. Here, we use four autosomal microsatellite DNA markers to investigate the demographic history of woolly mammoths (Mammuthus primigenius) in north-eastern Siberia from before 60000 years ago up until the species' final disappearance $c$. 4000 years ago. We identified two genetic groups, implying a marked temporal genetic differentiation between samples with radiocarbon ages older than 12 thousand radiocarbon years before present (ka) and those younger than 9 ka. Simulation-based analysis indicates that this dramatic change in genetic composition, which included a decrease in individual heterozygosity of approximately $30 \%$, was due to a multifold reduction in effective population size. A corresponding reduction in genetic variation was also detected in the mitochondrial DNA, where about $65 \%$ of the diversity was lost. We observed no further loss in genetic variation during the Holocene, which suggests a rapid final extinction event.
\end{abstract}

Keywords: ancient DNA, extinction, glaciation, Mammuthus primigenius, megafauna, palaeogenetics

Received 24 March 2011; revision received 30 January 2012; accepted 5 February 2012

\section{Introduction}

North-eastern (NE) Siberia has been identified as an important area for the evolution of the woolly mammoth (Lister \& Sher 2001). The earliest fossils attributable to that species have been found there, in deposits dated to

Correspondence: Veronica Nyström, Fax: +46 (0)8 5195 5181; E-mail: veronica.nystrom@nrm.se, or Love Dalén, Fax: +46 (0)8 5195 5181; E-mail: love.dalen@nrm.se c. $700 \mathrm{ka}$, well before the species spread widely across northern Eurasia and North America to become one of the most common large herbivores of the Late Quaternary (Lister et al. 2005). Several previous studies, employing both radiocarbon dating and ancient mitochondrial DNA (mtDNA) sequencing, have indicated that the last glaciation was a dynamic period for mammoths in NE Siberia, which included range contractions and expansions (Stuart et al. 2002, 2004), as well as genetic changes (Barnes et al. 2007; Gilbert et al. 2008). 
Furthermore, the woolly mammoth's range contracted from Europe and other regions c. $12 \mathrm{ka}$ (13.8 thousand calendar years before present; cal $\mathrm{kBP}$ ), and the latest known Eurasian populations were all in northern Siberia (Stuart et al. 2002; Nikolskiy et al. 2011). The last two known populations were on St. Paul Island in the Bering Sea (Veltre et al. 2004), until c. $5.6 \mathrm{ka}$ (6.4 cal kBP), and on Wrangel Island in the Arctic Ocean north of Chukotka (NE Siberia), until c. $3.7 \mathrm{ka}$ (4.0 cal kBP) (Vartanyan et al. 1993). Wrangel Island therefore served as a 'terminal refugium' (Lister \& Stuart 2008) where the last population of woolly mammoth became isolated and ultimately went extinct (Vartanyan et al. 1993). Radiocarbon data indicate the presence of mammoths on the island from at least c. $40 \mathrm{ka}$ until about $12 \mathrm{ka}$ (14 cal kBP) when they disappear from the adjacent mainland as well. Mammoths reappear in the fossil record on Wrangel from around $8.9 \mathrm{ka}$ (10 cal kBP) until extinction (Vartanyan et al. 2008). The significance of this gap in the fossil record has been debated: it may reflect local extirpation and recolonization (Vartanyan et al. 2005), a population bottleneck, or lack of preserved fossils. At any event, the reappearance of the mammoths at c. $10 \mathrm{cal} \mathrm{kBP}$ corresponds with the likely isolation of Wrangel Island by sea level rise (Vartanyan et al. 2005).

To date, most genetic studies of Late Pleistocene populations, including the woolly mammoth, have utilized mtDNA markers (Shapiro et al. 2004; Barnes et al. 2007; Gilbert et al. 2008; Campos et al. 2010; Nyström et al. 2010; Lorenzen et al. 2011). While this approach has proved useful in identifying population turnover in several Pleistocene species (Barnes et al. 2002; Hofreiter et al. 2007), mtDNA only provides information on a single gene tree, which may deviate from a species phylogeny owing to random lineage sorting, maternal inheritance and introgression. The lack of recombination also renders mtDNA markers highly subject to hitchhiking selection effects (Galtier et al. 2009), which could be particularly prevalent when populations are exposed to new climatic conditions (Balloux 2010). While any single nuclear locus may also suffer from these complications, the ability to sample a number of independent loci should provide more reliable results (Nielsen \& Beaumont 2009). Furthermore, evolutionary events occurring on smaller temporal scales may be better resolved through the investigation of more rapidly evolving markers such as nuclear microsatellites.

The aim of this study was twofold. First, we wanted to investigate the possibility of analysing autosomal microsatellite variation in Late Pleistocene and early Holocene samples. Nuclear DNA is more difficult to retrieve from ancient samples compared to mtDNA because it occurs in many fewer numbers per cell (Hofreiter et al. 2001). On the other hand, the excellent biomolecular preservation in permafrost specimens (e.g. Poinar et al. 2006) suggests that microsatellite genotyping might be possible. To explore this possibility, we screened a set of 15 microsatellite markers originally developed for Indian and African elephant (Supporting information). Four markers were found to be readily amplifiable and polymorphic. For these markers, we attempted to genotype 76 radiocarbon-dated mammoth specimens spanning an age of $>62-3.7 \mathrm{ka}$.

Second, using the microsatellite genotypes that were successfully obtained, as well as a supplemented data set of mtDNA sequences, we aimed to examine the population history of mammoths in NE Siberia. More specifically, we wanted to investigate whether the use of microsatellite markers gave similar results to those observed using mtDNA sequences (e.g. Barnes et al. 2007; Nyström et al. 2010) and whether it was possible to obtain estimates of the changes in effective population size $\left(N_{e}\right)$ that presumably took place at the end of the Pleistocene.

\section{Materials and methods}

\section{Samples and DNA analysis}

We used samples consisting of bones, teeth and tusks collected from Wrangel Island and Chukotka in NE Siberia (Table 1). Samples that had not been radiocarbon dated in previous studies (Vartanyan et al. 2008) were sent for radiocarbon dating at the Oxford Radiocarbon Accelerator Unit or the Angström Laboratory in Uppsala. All samples were drilled, and DNA was extracted from the powder following previously described methods and precautions against contamination (Nyström et al. 2010). Samples not previously analysed for mtDNA variation (reported in Nyström et al. 2010) were amplified and sequenced for a $741 \mathrm{bp}$ region of the mitochondrial genome using primers and polymerase chain reaction (PCR) conditions previously described in Barnes et al. (2007).

The microsatellite analysis involved an initial testing of 15 loci selected from a range of studies on African and Asian elephants (Nyakaana \& Arctander 1998; Comstock et al. 2000; Eggert et al. 2000; Kongrit et al. 2008; Table S1, Supporting information). Four of these loci were then selected for genotyping of all samples (see Data S1 for details). PCRs for the microsatellites were performed separately for each locus in $15 \mu \mathrm{L}$ volumes with $3 \mu \mathrm{L}$ of DNA extract, $0.2 \mu \mathrm{m}$ of each fluorescently labelled primer (Applied Biosystems), $0.64 \mathrm{~mm}$ dNTPs, $2.17 \mathrm{~mm}$ (loci FH67 and FH71) or $1.5 \mathrm{~mm}$ (loci EMU10 and EMU13) $\mathrm{MgCl}_{2}$ (Qiagen), $1 \times$ PCR-buffer (Qiagen) and 1.5 U HotStar Taq (Qiagen). PCR thermal cycling conditions were $15 \mathrm{~min}$ denaturation at $95^{\circ} \mathrm{C}, 55$ 
Table 1 List of samples used in this study. Samples are shown with their radiocarbon laboratory number and age in radiocarbon years, material used for DNA analysis, mtDNA haplotype and individual heterozygosity (values in brackets denote incomplete genotypes). Samples marked with an asterisk $\left(^{*}\right)$ indicate samples from Wrangel Island dated to the time period when Wrangel was part of the Beringian landmass. The number of successful genotypes for each specimen is shown for each of the four loci: EMU10 (1), EMU13 (2), FH67 (3) and FH71 (4)

\begin{tabular}{|c|c|c|c|c|c|c|c|}
\hline${ }^{14} \mathrm{C}$ laboratory no. & ${ }^{14} \mathrm{C}$ age & Material & Region & Locality & $\begin{array}{l}\text { mtDNA } \\
\text { haplotype }\end{array}$ & $\begin{array}{l}\text { Loci } \\
\text { scored }\end{array}$ & $\begin{array}{l}\text { Individual } \\
\text { heterozygosity }\end{array}$ \\
\hline OxA-20032 (P23349) & $>61600$ & Tooth & Chukotka & Krugloe Lake & W11 & $1,2,3,4$ & 1 \\
\hline OxA-20031 (P23348) & $>55700$ & Tusk & Chukotka & Ayon Island & W20 & $1,2,3,4$ & 0.5 \\
\hline OxA-20050 (P23366) & $>52000$ & Tusk & Chukotka & Rakvachan River basin & W17 & $1,3,4$ & $(0.33)$ \\
\hline LU-5180 & $\geq 50500$ & Tusk & Chukotka & Kyttyk Peninsula & W11 & 2,4 & $(0.5)$ \\
\hline OxA-20033 (P23350) & $50300 \pm 1000$ & Scapula & Chukotka & Kyttyk Peninsula & W25 & $1,2,3,4$ & 1 \\
\hline OxA-18498 & $49600 \pm 1000$ & Femur & Chukotka & Ngagleyngyveem-River & W22 & 2,4 & $(1)$ \\
\hline LU-5179 & $\geq 49000$ & Tusk & Chukotka & Kyttyk Peninsula & W11 & $1,2,3,4$ & 0.25 \\
\hline OxA-20038 (P23355) & $47700 \pm 750$ & Tooth & Chukotka & Kyttyk Peninsula & W14 & $1,2,3,4$ & 0.5 \\
\hline OxA-20034 (P23351) & $47450 \pm 700$ & Tusk & Chukotka & Kyttyk Peninsula & W26 & $1,2,3,4$ & 0.75 \\
\hline LU-5159 & $\geq 47400$ & Tusk & Chukotka & Nagleynenvaam River & W11 & $1,2,3,4$ & 0.5 \\
\hline OxA-20039 (P23356) & $46350 \pm 650$ & Femur & Chukotka & Kyttyk Peninsula & W11 & $1,2,3,4$ & 1 \\
\hline Ua-13365 & $>38000$ & Tooth & Wrangel* & & W1 & $1,2,3,4$ & 0.75 \\
\hline LU-3511 & $37080 \pm 1650$ & Bone & Wrangel* & & W2 & $1,2,3,4$ & 0.5 \\
\hline OxA-18497 & $31470 \pm 180$ & Tusk & Chukotka & Ngagleyngyveem-River & W21 & $1,2,3,4$ & 0.75 \\
\hline LU-5168 & $28600 \pm 460$ & Tooth & Chukotka & Nagleynenvaam River & W24 & $1,2,3,4$ & 0.75 \\
\hline OxA-20036 (P23353) & $26240 \pm 120$ & Tooth & Chukotka & Kyttyk Peninsula & W13 & 2,4 & (1) \\
\hline OxA-20047 (P23363) & $26180 \pm 110$ & Tusk & Chukotka & Pineyveem River & W18 & $1,2,3,4$ & 0.5 \\
\hline OxA-20030 (P23347) & $25610 \pm 110$ & Tibia & Chukotka & Ayon Island & W27 & $1,2,3,4$ & 0.5 \\
\hline GIN-8257 & $22400 \pm 200$ & Bone & Wrangel $^{*}$ & & W3 & $1,2,4$ & $(1)$ \\
\hline LU-2807 & $20000 \pm 110$ & Tooth & Wrangel* & & W4 & $1,2,3,4$ & 0.75 \\
\hline OxA-20042 (P23359) & $19850 \pm 90$ & Tooth & Chukotka & Mosey Island & W12 & $1,2,3,4$ & 0.75 \\
\hline OxA-20049 (P23365) & $19840 \pm 75$ & Femur & Chukotka & Rakvachan River & W16 & $1,2,3,4$ & 0.75 \\
\hline LU-4467 & $15040 \pm 130$ & Tusk & Chukotka & Pegtymel River & W12 & 1,4 & (1) \\
\hline LE-5252 & $14240 \pm 220$ & Vertebra & Chukotka & Ayon Island & W23 & $1,2,4$ & $(0.67)$ \\
\hline OxA-20048 (P23364) & $13935 \pm 50$ & Tusk & Chukotka & Pineyveem River & W19 & $1,2,3,4$ & 0.75 \\
\hline OxA-20046 (P23362) & $12385 \pm 45$ & Humerus & Chukotka & Pineyveem River & W15 & $1,2,3,4$ & 0.75 \\
\hline LU-2823 & $12010 \pm 110$ & Tooth & Wrangel $^{*}$ & & W6 & $1,2,3,4$ & 0.5 \\
\hline AA60049 & $8870 \pm 100$ & Bone & Wrangel Island & & W1 & $1,2,3,4$ & 0.25 \\
\hline Ua-13377 & $8030 \pm 75$ & Tooth & Wrangel Island & & W1 & $1,2,3,4$ & 0.5 \\
\hline LU-4473 & $7850 \pm 80$ & Tusk & Wrangel Island & & W1 & $1,3,4$ & $(0.33)$ \\
\hline GIN-6995 & $7710 \pm 40$ & Tusk & Wrangel Island & & W1 & $1,2,3,4$ & 0.25 \\
\hline Ua-13372 & $7510 \pm 80$ & Tooth & Wrangel Island & & W1 & $1,2,3,4$ & 0.5 \\
\hline LU-2809 & $7250 \pm 60$ & Tooth & Wrangel Island & & W7 & 1,3 & (1) \\
\hline LU-2746 & $7040 \pm 60$ & Tusk & Wrangel Island & & W1 & $1,2,3,4$ & 0.5 \\
\hline LU-3515 & $6830 \pm 40$ & Bone & Wrangel Island & & W1 & $1,2,3,4$ & 0.75 \\
\hline GIN-6997 & $6690 \pm 60$ & Tusk & Wrangel Island & & W1 & $1,2,3,4$ & 1 \\
\hline Ua-13361 & $6560 \pm 75$ & Tooth & Wrangel Island & & W1 & $1,2,3,4$ & 0.5 \\
\hline LU-4449 & $6560 \pm 60$ & Tusk & Wrangel Island & & W1 & $1,2,3,4$ & 0.5 \\
\hline Ua-13360 & $6530 \pm 70$ & Tooth & Wrangel Island & & W1 & $1,3,4$ & $(0.33)$ \\
\hline AA40666 & $6499 \pm 66$ & Bone & Wrangel Island & & W1 & $1,2,3,4$ & 0.5 \\
\hline LU-2799 & $6260 \pm 50$ & Tooth & Wrangel Island & & W1 & $1,2,3,4$ & 0.25 \\
\hline LU-4474 & $5910 \pm 50$ & Tusk & Wrangel Island & & W1 & $1,2,3,4$ & 0.25 \\
\hline GIN-6988 & $5610 \pm 40$ & Tusk & Wrangel Island & & W1 & $1,2,3,4$ & 0.25 \\
\hline LU-2742 & $5310 \pm 90$ & Tusk & Wrangel Island & & W8 & $1,2,4$ & $(0.67)$ \\
\hline Ua-13368 & $4730 \pm 65$ & Tooth & Wrangel Island & & W1 & 1,4 & $(0.5)$ \\
\hline Ua-34664 & $4715 \pm 35$ & Bone & Wrangel Island & & W10 & $1,2,3,4$ & 0.25 \\
\hline Ua-13373 & $4675 \pm 75$ & Tooth & Wrangel Island & & W1 & $1,2,3,4$ & 0.25 \\
\hline Ua-13378 & $4475 \pm 60$ & Tooth & Wrangel Island & & W9 & $1,2,3,4$ & 0.75 \\
\hline LU-2756 & $4400 \pm 40$ & Tusk & Wrangel Island & & W1 & $1,2,3,4$ & 0.5 \\
\hline AA40667 & $4389 \pm 46$ & Bone & Wrangel Island & & W10 & $1,2,3,4$ & 0.75 \\
\hline GIN-6989 & $4370 \pm 40$ & Tusk & Wrangel Island & & W1 & $1,2,4$ & $(0.33)$ \\
\hline Ua-13362 & $4260 \pm 75$ & Tooth & Wrangel Island & & W10 & $1,3,4$ & $(0.33)$ \\
\hline
\end{tabular}


Table 1 Continued

\begin{tabular}{|c|c|c|c|c|c|c|c|}
\hline${ }^{14} \mathrm{C}$ laboratory no. & ${ }^{14} \mathrm{C}$ age & Material & Region & Locality & $\begin{array}{l}\text { mtDNA } \\
\text { haplotype }\end{array}$ & $\begin{array}{l}\text { Loci } \\
\text { scored }\end{array}$ & $\begin{array}{l}\text { Individual } \\
\text { heterozygosity }\end{array}$ \\
\hline Ua-13375 & $4210 \pm 70$ & Tooth & Wrangel Island & & W1 & $1,2,3,4$ & 0.25 \\
\hline LU-4448 & $4120 \pm 110$ & Tusk & Wrangel Island & & W1 & $1,2,3,4$ & 0.25 \\
\hline Ua-13369 & $4085 \pm 65$ & Tooth & Wrangel Island & & W1 & 1,3 & $(0.5)$ \\
\hline GIN-6985 & $3920 \pm 40$ & Tusk & Wrangel Island & & W1 & $1,2,3,4$ & 0.75 \\
\hline AA40665 & $3905 \pm 47$ & Tooth & Wrangel Island & & W1 & $1,2,3,4$ & 0.25 \\
\hline LU-2741 & $3730 \pm 40$ & Tusk & Wrangel Island & & W1 & $1,2,3,4$ & 0.5 \\
\hline Ua-13366 & $3685 \pm 60$ & Tooth & Wrangel Island & & W1 & $1,2,3,4$ & 0.25 \\
\hline
\end{tabular}

GenBank accession numbers for matching sequences: W1: AM746196; W2: GU984770; W3: GU984771; W4: AM746174; W6: GU984774; W7: EU153449; W8: GU984776; W9: GU984777; W10: GU984778; W11: AM746172; W12: AM746182; W13: JQ394825; W14: JQ394826; W15: JQ394827; W16: JQ394828; W17: JQ394829; W18: AM746163; W19: JQ394830; W20: JQ394831; W21: JQ394832; W22: JQ394833; W23: EU153445; W24: JQ394834; W25: JQ394835; W26: JQ394836; W27: JQ394837.

cycles of $30 \mathrm{~s}$ denaturation at $94^{\circ} \mathrm{C}, 40 \mathrm{~s}$ annealing at $53^{\circ} \mathrm{C}$ (FH67 and $\left.\mathrm{FH} 71\right), 56^{\circ} \mathrm{C}$ (EMU13) or $57^{\circ} \mathrm{C}$ (EMU10), $1 \mathrm{~min}$ extension at $72^{\circ} \mathrm{C}$ and a single $30 \mathrm{~min}$ extension step at $72^{\circ} \mathrm{C}$. PCR products were diluted 100 300-fold and run on an ABI 3130xl automated sequencer (Applied Biosystems). Fragment sizes were determined using the LIZ-500 size standard (Applied Biosystems) and analysed with the software GENOTYPER v. 3.7 (Applied Biosystems).

\section{Ancient DNA authentication}

For the mtDNA sequences, we followed the approach of Barnes et al. (2007) with repeated amplification and sequencing of $44 \%$ of all base positions. No discrepancies were found among replicates, suggesting a large number of starting molecules in the PCRs, which is not surprising given that the samples also yielded nuclear DNA. During the microsatellite analysis, all genotypes were replicated at least twice to monitor for allelic dropout (i.e. when one of the alleles at a heterozygous locus fails to amplify). After the first two runs, we estimated the probability of falsely accepting a homozygote after $n$ replicates (Gagneux et al. 1997). Samples that appeared homozygous after the first two runs were thereafter replicated until the probability of allelic dropout for each locus was lower than 0.05. Samples were recognized as heterozygotes when both alleles had appeared in two independent runs. Moreover, we performed a second set of statistical analyses where individuals that were difficult to score for all four loci were excluded, to ensure that the inclusion of potentially 'problematic individuals' did not affect the results. Thus, the steps taken here to minimize the effect of genotyping errors are consistent with the three criteria recently outlined in Allentoft et al. (2011), where it is suggested that the rate of allelic dropout should be kept below 5\% (criterion 1), heterozygotes should be scored when observed, or preferably when both alleles have been scored at least twice (criterion 2) and that 'problematic individuals' are removed from the data set (criterion 3 ). To investigate whether the age of the samples affected the microsatellite amplification success rate, we performed a Spearman rank correlation analysis using the software $R(R$ Development Core Team 2008) where radiocarbon ages were compared with the number of loci successfully amplified for each specimen.

\section{mtDNA data analysis}

All mtDNA sequences were aligned and assigned to haplotypes in BIOEDIT v.7.0.5.2 (Hall 1999). To illustrate the temporal change in mtDNA haplotypes, we used the script TempNet (Prost \& Anderson 2011) in $R$ ( $\mathrm{R}$ Development Core Team 2008) to construct a statistical parsimony network for two time periods $(>62-12$ and 9-3.7 ka). We also calculated haplotype diversities for the two time periods using ARLEQUIN v. 3.5.1.2 (Excoffier \& Lischer 2010).

\section{Microsatellite genetic differentiation}

We used the Bayesian clustering approach implemented in STRUCTURE v. 2.3.3 (Pritchard et al. 2000) to infer the most probable number of genetic clusters $(K)$ in our data set by calculating posterior likelihood values for $K=1-5$. Analyses were run without the use of prior population information, using the admixture and correlated allele frequency models with a burn-in length of $10^{5}$ followed by $10^{6}$ iterations. The number of clusters chosen was determined on the basis of the highest likelihood value calculated following Bayes' Rule (Pritchard et al. 2000). We ran the analyses for both the complete data set $(n=59)$ and after excluding individuals containing missing data $(n=44)$ using ten replicates for each analysis. Average pairwise similarities among rep- 
licates $\left(H^{\prime}\right)$ were computed using the software CLUMPP (Jakobsson \& Rosenberg 2007).

Since the population genetic model underlying STRUCTURE does not accommodate genetic differentiation arising from temporal heterogeneity between samples (Depaulis et al. 2009), we also investigated genetic differentiation using principal component analysis (PCA), which is not based on a particular model. Moreover, this also allows PCA to be used in simulation-based comparisons of empirical genetic differentiation with the genetic differentiation expected from temporal structure alone. PCA was performed using the PRCOMP function in $\mathrm{R}$ ( $\mathrm{R}$ Development Core Team 2008). Before the analyses, we converted the microsatellite data for individuals with no missing data by scoring the presence (in single or double copies) or absence of each allele at each locus and individual (e.g. Patterson et al. 2006).

\section{Microsatellite genetic variation}

The software ARLEQUIN v. 3.5.1.2 (Excoffier \& Lischer 2010) was used to test for linkage disequilibrium and deviations from Hardy-Weinberg proportions in the two groups inferred from the clustering and PC-analyses. We tested for linkage disequilibrium in the four loci, using 16000 permutations and 10 initial conditions. After applying Bonferroni correction for multiple testing (Rice 1989), one combination of loci (FH67 and FH71) deviated from linkage equilibrium $(P<0.001)$. The significance levels of deviations from Hardy-Weinberg proportions were computed using a Markov chain with a chain length of $10^{5}$ and 3000 dememorization steps. In each temporally separated group, one locus (FH67 and EMU10, respectively) showed a significant deviation from Hardy-Weinberg proportions after Bonferroni correction, caused by heterozygote deficit (Table 2). This could either be a consequence of allelic dropout in the data set (Morin et al. 2009) or gradual genetic drift within each time period. In any case, when

Table 2 Genetic variation. Observed $\left(H_{\mathrm{O}}\right)$ and expected heterozygosity $\left(H_{\mathrm{E}}\right)$ in each locus and time period. The asterisk $\left(^{*}\right)$ indicates significant $P$-values after Bonferroni correction $(P<0.01)$

\begin{tabular}{|c|c|c|c|c|}
\hline \multirow[b]{2}{*}{ Locus } & \multicolumn{2}{|c|}{$>62-12 \mathrm{ka}(n=27)$} & \multicolumn{2}{|c|}{$9-3.7 \mathrm{ka}(n=32)$} \\
\hline & $H_{\mathrm{O}}$ & $H_{\mathrm{E}}$ & $H_{\mathrm{O}}$ & $H_{\mathrm{E}}$ \\
\hline EMU10 & 0.67 & 0.53 & 0.19 & $0.28^{*}$ \\
\hline EMU13 & 0.64 & 0.71 & 0.50 & 0.42 \\
\hline FH67 & 0.43 & $0.46^{*}$ & 0.48 & 0.41 \\
\hline FH71 & 0.96 & 0.92 & 0.67 & 0.70 \\
\hline Mean \pm SD & $0.67 \pm 0.22$ & $0.65 \pm 0.21$ & $0.46 \pm 0.20$ & $0.45 \pm 0.18$ \\
\hline
\end{tabular}

excluding individuals containing missing data from the analyses, no significant deviations from linkage equilibrium or Hardy-Weinberg proportions were found (Table S4, Supporting information).

Genetic variation was measured as allelic richness and the mean number of private alleles per locus, corrected for variation in sample sizes, using ADZE v. 1.0 (Szpiech et al. 2008). Since genetic analyses of samples covering large time periods can be biased by heterochrony between subsets (Depaulis et al. 2009), we also calculated the mean individual heterozygosity (i.e. mean observed heterozygosity), which is not affected by this bias.

\section{Simulations}

While several methods exist to estimate effective population size $\left(N_{e}\right)$ between temporal samples (e.g. Krimbas \& Tsakas 1971; Waples 1989; Anderson et al. 2000; Wang 2001; Berthier et al. 2002; Beaumont 2003), these methods typically require samples to be organized in discrete time points, an assumption that would be difficult to accommodate given the highly heterogeneous distribution of radiocarbon dates that have been obtained for the samples used in this study (Vartanyan et al. 2008; Table 1). We therefore employed a simulation-based approach to investigate whether changes in $N_{e}$ could explain the patterns of genetic differentiation observed in the clustering and PCA, as well as the observed levels of genetic variation at different time points. To not rely solely on arbitrarily delimited temporal groups, we explicitly took temporally continuous differentiation into account by using summary statistics computed from PC loadings. We used compass (Jakobsson 2009), a software for coalescent simulation of temporal samples under different demographic models, to simulate four microsatellite loci in samples from a continuous population with exactly the same time intervals as the radiocarbon ages of the studied mammoth fossils (excluding individuals with missing data). For each sample, we simulated two independent lineages of the same age and combined the two gene copies into a diploid genotype. We assumed a generation time of 15 years (Sukumar 1989) and converted the data generated under the infinite sites model implemented by COMPASS to microsatellite genotypes with a custom program assuming a stepwise model of mutation (available on request). The algorithm proceeds by generating a number of mutations for the sample ('segregating sites' for a single, fully linked locus using COMPAss), and for each mutation, randomly increasing $(+1)$, or decreasing $(-1)$ the microsatellite repeat length by one unit from an arbitrarily selected starting length of 100 .

We estimated $N_{e}$ through time in an approximate Bayesian framework using a rejection algorithm (Tavaré 
et al. 1997; Beaumont 2010) under two different models (Fig. 1). First, we assumed a two-epoch demographic model with uniform priors on $N_{e}$ before and after $12 \mathrm{ka}$. Second, we included the possibility of a bottleneck between 9 and $12 \mathrm{ka}$ by estimating $N_{e}$ in three time intervals: 0-9 ka $\left(N_{\mathrm{w}}\right), 9-12 \mathrm{ka}\left(N_{\mathrm{b}}\right)$ and $>12 \mathrm{ka}$ $\left(N_{\mathrm{a}}\right)$. These time intervals were chosen partly on the basis of the fossil record [with $12 \mathrm{ka}$ corresponding to the isolation of Wrangel Island and 9-12 ka corresponding to a period for which no mammoth remains have been found (Vartanyan et al. 2008)] and partly on our analyses of genetic differentiation. Initial exploratory simulations used a uniform prior over $N_{e}=10-200000$ in each time epoch, but final estimates are based on prior distributions $N_{e}=200-50000$. We experimented with mutation rates ranging from $10^{-3}$ to $10^{-5}$ and found qualitative evidence for a population bottleneck for this entire range of assumptions, but chose to fix the mutation rate to $10^{-4}$ for all subsequent analyses because this value resulted in summary statistics with the shortest Euclidian distance to our empirical data. From 10000000 simulations, we ranked the replicates according to the Euclidian distance between observed and empirical summary statistics, and estimated marginal posterior densities of $N_{e}$ in each epoch from the top-ranked $0.01 \%$ simulations using an Epanechnikov kernel (Beaumont et al. 2002; Beaumont 2010). PCA was performed for each simulation replicate as described above. Summary statistics were computed from both empirical and simulated data using custom scripts. We used the following summary statistics for each temporal sample group (pre- and post-12 ka): the mean of PC1, the standard deviation of $\mathrm{PC} 1$, the number of private alleles, the average number of alleles per sample group

(a)

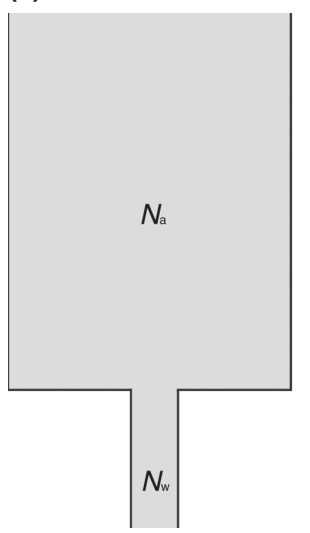

(b)

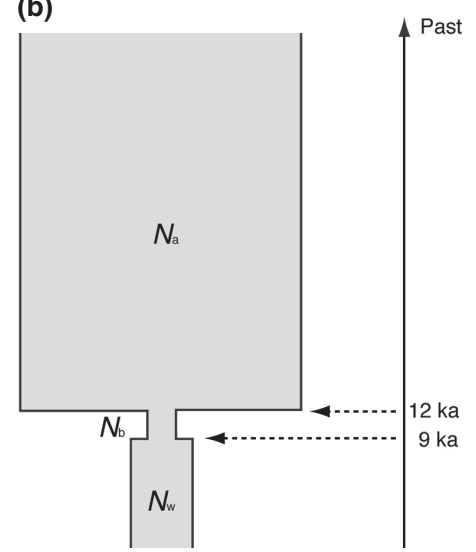

Fig. 1 Demographic models. The effective population size in the time intervals $0-9,9-12$ and $>12$ ka are denoted $N_{\mathrm{w}}, N_{\mathrm{b}}$ and $N_{\mathrm{a}}$, respectively, shown for (a) the two-epoch model and (b) the three-epoch model. and the expected heterozygosity. In addition, for the total sample, we used the correlation between age and PC1, and $\mathrm{F}_{\mathrm{ST}}$ between the two temporal groups (eqn 5.3; Weir 1996). This sums to a total of 12 summary statistics, of which five are based on PCA. We note that while several of these summary statistics are sample size-dependent, sample size effects are negligible when empirical and simulated samples of exactly the same number are compared.

To investigate the fit of inferred models to the empirical data, we performed model validation by drawing $N_{e}$ parameters for each time period directly from the posterior marginal distribution and analysing the resulting summary statistic distributions (Beaumont 2010). From 10000 simulations based on each model, we computed the marginal posterior predictive distribution of each of the 12 summary statistics and tested whether the empirically obtained summary statistics fell within the $95 \%$ quantile of the data generated by the models.

\section{Results and discussion}

The microsatellite genotyping was successful for 59 of the 76 samples (Table 1). We observed a weak but significant decrease in amplification success with specimen age $\left(\rho^{2}=0.06, \quad P=0.03\right)$. Although this correlation should be expected, several previous ancient DNA studies have failed to demonstrate such a relationship between time and DNA degradation (e.g. Pääbo 1989; Poinar et al. 1996; Colson et al. 1997). One reason for this might be that most earlier studies have analysed samples from a variety of sampling locations, with different environmental conditions (e.g. temperature, humidity and $\mathrm{pH}$ ), which may have obscured the effects of time itself. In contrast, the samples in this study all derived from permafrost deposits and originate from the same geographic region.

The rate of allelic dropout across all loci was $31 \%$. There was, however, no difference in the rate of allelic dropout among sampling locations or between older $(>12 \mathrm{ka})$ and more recent $(<9 \mathrm{ka})$ samples $\left(\chi^{2}=0.07\right.$, $P=0.80 ;$ and $\chi^{2}=2.12, P=0.15$, respectively). The overall rate of allelic dropout reported here is somewhat higher than those observed for museum specimens that are 50-200 years old (Flagstad et al. 2003; Nyström et al. 2006; but see Wandeler et al. 2003). Nonetheless, the probability of falsely scoring a heterozygous genotype as a homozygote was $<0.01$ for three and $<0.05$ for one of the loci after three replicates (Table S2, Supporting information). Moreover, allele sizes were consistent between replicates, and we did not observe more than two alleles in any of the individual genotypes, suggesting a very low frequency of false alleles in the data set. Overall, these results suggest that 
microsatellite genotyping is feasible on permafrost samples several tens of thousands of years old, and that the overall success rate is high enough to make populationlevel studies possible.

Clustering analyses with no a priori sample information (Pritchard et al. 2000) identified two genetic clusters in the data set (Table S3, Supporting information). Replicates $(n=10)$ yielded high average pairwise similarities (Jakobsson \& Rosenberg 2007), both within each analysis $\left(H^{\prime}>0.99\right)$ and when the full data set was compared with the one where individuals with missing data was excluded $\left(H^{\prime}=0.97\right)$. The two genetic clusters align with the temporal partitioning of samples, that is, samples with radiocarbon ages older than $12 \mathrm{ka}$ were assigned to one cluster and samples younger than $9 \mathrm{ka}$ grouped in the second cluster (Figs 2a and S1, Supporting information). The PCA also gave a clear separation between samples older than $12 \mathrm{ka}$ and those younger than $9 \mathrm{ka}$ (Fig. 2b), and the first principal component was significantly correlated with sample radiocarbon age over the whole time span (Pearson correlation coefficient: $-0.72, P=2.73 \times 10^{-8}$, Fig. 2c), but not within the periods $>62-12 \mathrm{ka}(R=-0.30, P=0.20)$ or $9-12 \mathrm{ka}$
$(R=0.30, P=0.15)$. While spatial population structure could also give rise to these patterns, we found no evidence of differentiation along PC1 between samples from Chukotka and Wrangel aged $>12 \mathrm{ka}$ (two-tailed t-test: $P=0.66)$, in contrast to samples obtained from Wrangel dated to before $12 \mathrm{ka}$ and after $9 \mathrm{ka}$, which are significantly differentiated on PC1 (Fig. 2c: $P=0.0097$ ). Thus, these results indicate a marked change in allele frequencies coinciding with the isolation of mammoths on Wrangel Island. Moreover, the results from the microsatellite analyses are consistent with those observed in the mtDNA data set, where a change in haplotype frequencies is also observed between the two time periods (Fig. 3).

The observed change in genetic composition was accompanied by an apparent reduction in autosomal genetic variation around the Pleistocene/Holocene transition (Fig. 4). The mean individual heterozygosity (Tables 2 and S4, Supporting information) was significantly higher in samples from before $12 \mathrm{ka}$ than in those from after $9 \mathrm{ka}\left(H_{\mathrm{o}}=0.67\right.$ and 0.46 , respectively, $\left.t_{116}=5.58, P<0.0001\right)$. Similarly, allelic richness based on a sample size of 20 diploid individuals was also

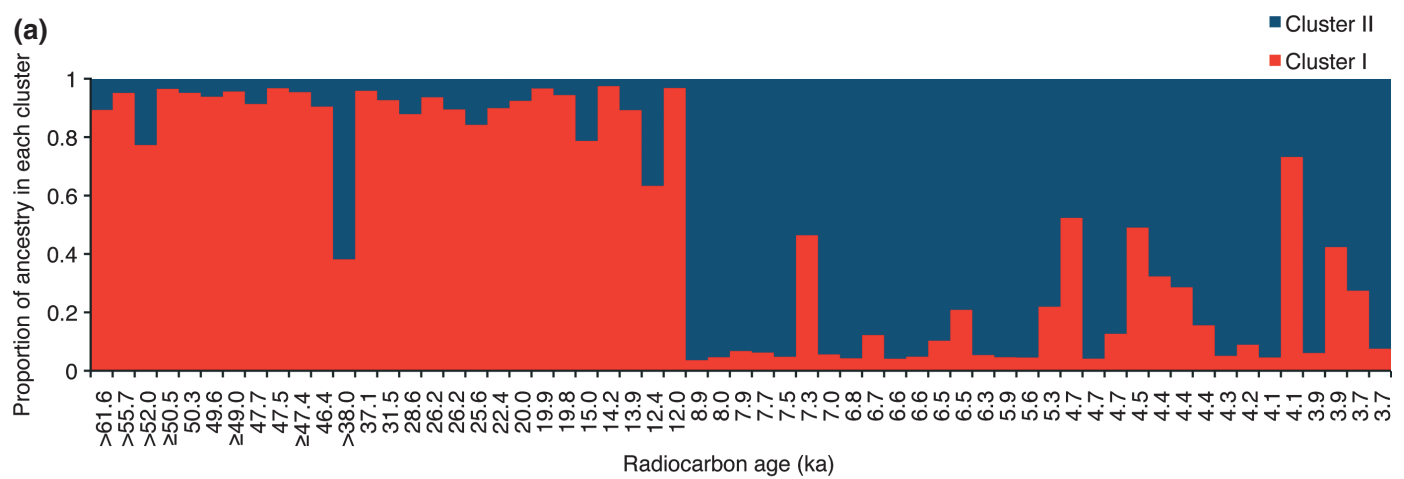

(b)

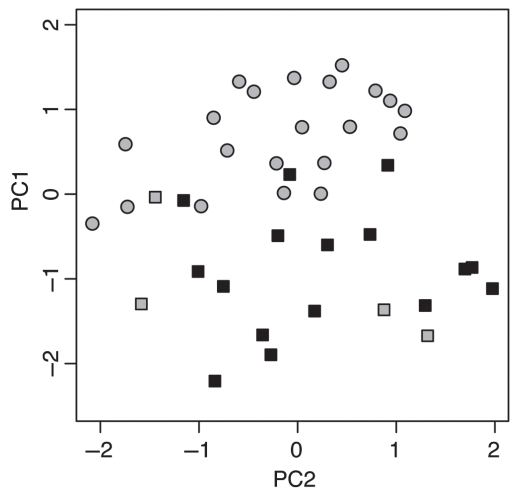

(c)

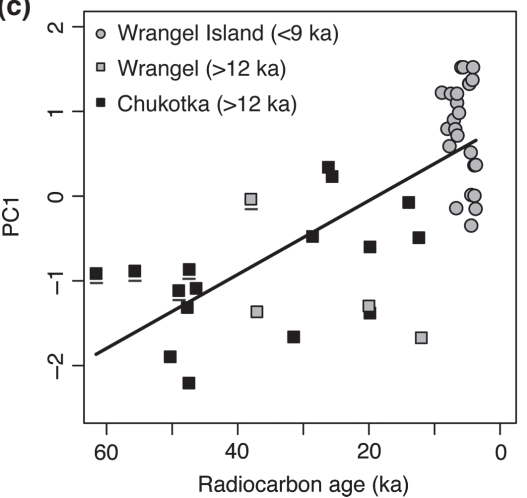

Fig. 2 Analysis of genetic differentiation. (a) Assignment of individuals to genetic clusters. The figure shown is based on the mean Q-values computed in CLUMPP from 10 clustering solutions obtained in STRUCTURE assuming two clusters. Each vertical bar represents one individual and shows its inferred cluster membership. The radiocarbon age (ka) is given below each individual. (b) Principal components analysis. Samples from before (black) and after (grey) $12 \mathrm{ka}$ are differentiated along PC1. (c) Correlation between PC1 and radiocarbon age (Pearson correlation coefficient: $-0.72, P=2.73 \times 10^{-8}$ ), where underlined squares represent samples with infinite radiocarbon dates. 


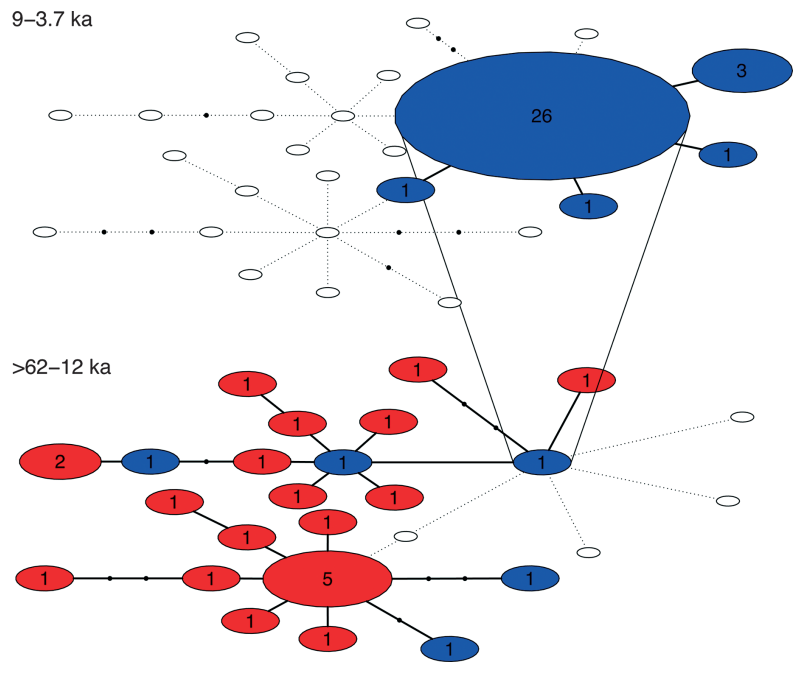

Fig. 3 A statistical parsimony network for two time periods (>62-12 ka and 9-3.7 ka). Blue haplotypes are from Wrangel and red haplotypes are from Chukotka. Haplotypes present in both time periods are connected with lines. Each branch represents one mutational step, and black circles represent missing haplotypes. Haplotypes missing only in one particular time period are shown as white ellipses. The number of individuals belonging to a particular haplotype is written within the ellipses.

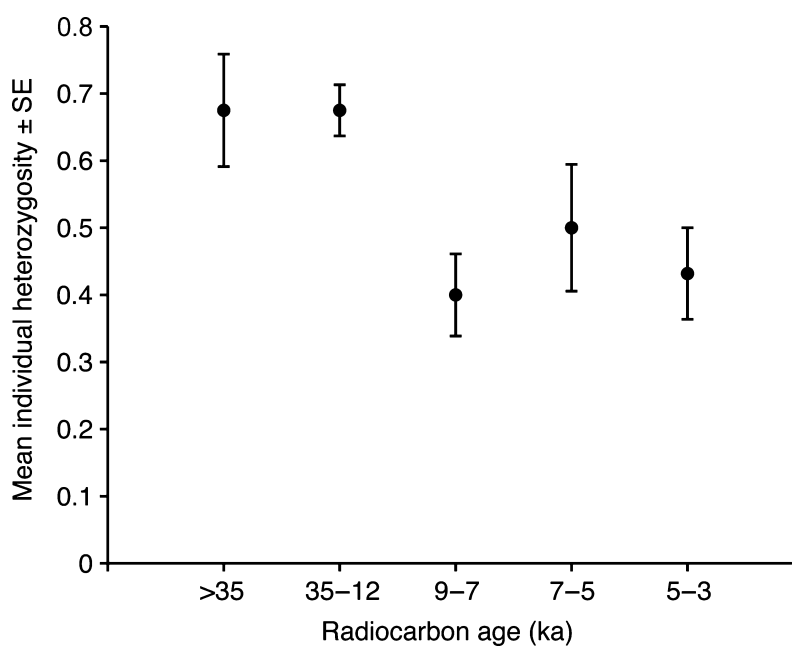

Fig. 4 Genetic variation through time. Mean individual heterozygosity with standard errors in different time periods. Samples with missing data were excluded.

higher before $12 \mathrm{ka}$ (5.61 vs. 3.55). We also found a higher number of private alleles per locus before $12 \mathrm{ka}$ than after $9 \mathrm{ka}(2.60 \mathrm{vs} .0 .54)$, and of these, the majority were found at low frequencies (Fig. S2 and Table S5, Supporting information). A significant reduction in diversity $\left(t_{57}=30.7, P<0.001\right)$ was also observed in the mtDNA, where the haplotype diversity before $12 \mathrm{ka}$ was $0.97 \quad( \pm \mathrm{SE}=0.005)$ and after $9 \mathrm{ka}$ was 0.34
$( \pm S E=0.018)$. The loss in diversity appears to have been greater in mtDNA compared to the microsatellites, which is not surprising given that the mode of inheritance and haploid nature of mtDNA leads to a fourfold higher genetic drift compared to autosomal markers. Taken together, the results from both types of markers are in agreement with a reduction in effective population size $\left(N_{e}\right)$, which often is accompanied by the loss of rare alleles (Allendorf \& Luikart 2007) and suggests either a bottleneck or a local extinction followed by recolonization of Wrangel Island.

To investigate possible demographic scenarios that could give rise to the patterns observed in the empirical data, we used serial coalescent simulations (Jakobsson 2009) to estimate changes in $N_{e}$ over different epochs using an approximate Bayesian framework (Fig. 1). We based our inferences on the observations of genetic variation, explicitly taking temporal differentiation into account using PCA (see Materials and methods). Assuming a single continuous population partitioned into two time epochs with potentially different population sizes, we estimated a severe reduction in $N_{e}$ from an ancestral size of c. 8500 to c. 500 in the last $12 \mathrm{ka}\left(95 \%\right.$ credible intervals for $N_{e}$ were 5000-23 400 and 300-2200, respectively; Fig. 5a). Thus, a clear, approximately tenfold reduction in population size, as the range shrank from encompassing both the mainland and Wrangel to Wrangel Island only, seems to be a likely demographic scenario. This model of a reduction in population size was also able to recapitulate the observed differences in genetic variation and differentiation in our posterior predictive analysis (Figs S3-S5, Supporting information), indicating that the model provides a good fit to the empirical data. The alternative demographic scenario: extinction on Wrangel followed by recolonization by a small number of founders, seems less likely. Under this scenario, we would have expected to recover a marginal posterior distribution indicating a smaller effective population size in the middle epoch $\left(N_{\mathrm{b}}\right)$ compared to the final epoch $\left(N_{\mathrm{w}}\right.$; Figs 1 and 5), since a founder event presumably would have entailed an initially much lower $N_{e}$ followed by a demographic increase. While the statistical power to separate between these two scenarios may be limited, the estimated reduction in size between 12 and $9 \mathrm{ka}$ (c. 14-10 cal kBP) in the threeepoch model was similar to the two-epoch model, and we found no evidence for a recovery in $N_{e}$ in the last epoch ( $<9 \mathrm{ka})$ (Fig. 5b). Furthermore, a simple reduction in population size is also consistent with the mitochondrial data showing that mtDNA variation in the more recent epoch is largely a subset of the variation in the more ancient epoch (Fig. 3; see also Nyström et al. 2010). 

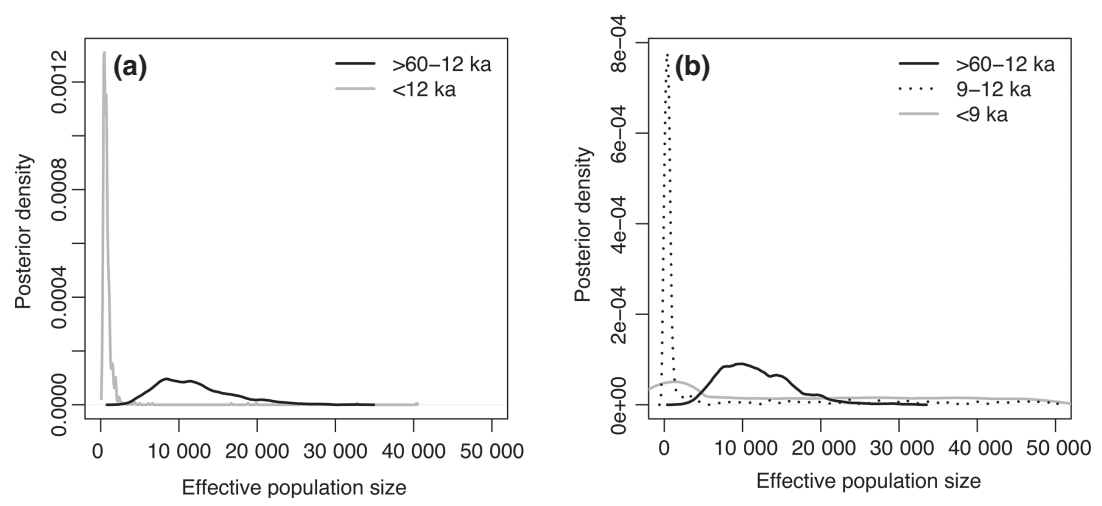

Fig. 5 Results of approximate Bayesian demographic inference. The marginal posterior distribution of effective population size is given for different time spans in (a) the two-epoch model and (b) the three-epoch model. The method uses conventional summary statistics of genetic variation together with summary statistics of continuous temporal genetic differentiation based on principal components analysis (see Materials and methods).

Previous studies have identified two mitochondrial lineages of woolly mammoth (clade 1 and clade 2 ) in northern Siberia (Barnes et al. 2007; Debruyne et al. 2008; Gilbert et al. 2008). Both lineages were present until c. $40 \mathrm{ka}$ when clade 2 disappeared. It has been suggested that the loss of clade 2 may have been a consequence of a local population bottleneck or local extinction in NE Siberia that affected all mammoths, including those belonging to mtDNA clade 1 (Gilbert et al. 2008). Consequently, even though none of our genotyped samples belonged to the clade $2 \mathrm{mtDNA}$ lineage (Fig. 3), one would still expect this hypothesized population turnover to have left a signature in the autosomal genome. However, we find no support for a major genetic bottleneck between 62 and 12 ka (Fig. 2). Instead, our results are in accordance with previous inferences of demographic change in mammoths, which have suggested a relatively constant (Barnes et al. 2007; Debruyne et al. 2008), or increasing (Lorenzen et al. 2011), population size in Beringia during MIS 3 (60$25 \mathrm{ka}$ ), despite the loss of clade 2. Further, our credible range obtained for $N_{e}$ is also in line with the 100039000 estimated by Barnes et al. (2007), but differs from the 40000 - 150000 estimated by Debruyne et al. (2008). It should, however, be noted that the analysis of only four autosomal loci may result in insufficient resolution to detect the population turnover hypothesized by Gilbert et al. (2008), and that our $N_{e}$ estimates rely on assumptions about microsatellite mutation rate. Nonetheless, they are the first that are based on multilocus data rather than single-locus mitochondrial DNA.

Following the rise in sea levels that accompanied the end of the Pleistocene, mammoths became isolated on Wrangel Island around $9 \mathrm{ka}$ (10 cal kBP) (Fairbanks 1989; Vartanyan et al. 2008). The results from our microsatellite analysis suggest an $N_{e}$ of approximately 500 during the period that mammoths were isolated on
Wrangel Island. This estimate is roughly in line with previous estimates suggesting a carrying capacity of 149-819 mammoths on Wrangel Island (Nyström et al. 2010). In very small and isolated populations, genetic drift can lead to the loss of genetic variation, and in some cases even fixation of microsatellite alleles and mtDNA haplotypes (Aguilar et al. 2004; Allendorf \& Luikart 2007). However, despite the comparatively small $N_{e}$ on Wrangel Island, we observe no further loss of genetic variation during the 5000 years preceding the final extinction (Fig. 4; Table 1). Consequently, our results are consistent with theoretical expectations for how small a population can be and still retain its genetic variation and evolutionary potential $\left(N_{e}>500\right.$; Franklin \& Frankham 1998). It therefore appears that Wrangel Island was just about large enough to support a genetically stable mammoth population, suggesting that the final extinction was not a delayed outcome of an inevitable process (e.g. an extinction debt caused by inbreeding and loss of genetic variation).

In conclusion, this study not only demonstrates the feasibility of microsatellite DNA genotyping of permafrost samples from Late Pleistocene populations, but also provides a more detailed picture of the genetic changes that occurred in woolly mammoths over time. The use of autosomal markers has allowed us to identify two distinct and temporally separated genetic groups in NE Siberia, indicative of a demographic event corresponding roughly with the Pleistocene/Holocene transition. The most probable demographic scenario giving rise to this pattern was found to be a sharp decrease in $N_{e}$ in a single continuous population, most likely due to mammoths becoming isolated on Wrangel Island when sea levels rose at the end of the Pleistocene. Although both autosomal and mtDNA genetic variation was lost during this event, no further loss of diversity was observed during the ensuing period of 
isolation on Wrangel Island. This suggests that the final extinction was caused by a rapid change in the mammoth's environment, such as the arrival of humans or a change in climate, rather than a gradual decline in population size.

\section{Acknowledgements}

We thank Keyvan Mirbakhsh and Eleftheria Palkopoulou for laboratory assistance, and Lisette Waits for comments on an earlier draft of the manuscript. Genetic analyses were funded through the EU Marie Curie Intra-European Fellowship FP6 041545 and from Formas through the EU Biodiversa CLIMIGRATE project. L.D. acknowledges funding from the Swedish Research Council. Radiocarbon dating was funded through grant NF/2008/1/17 from the NERC radiocarbon facility.

\section{References}

Aguilar A, Roemer G, Debenham S, Binns M, Garcelon D, Wayne RK (2004) High MHC diversity maintained by balancing selection in an otherwise genetically monomorphic mammal. Proceedings of the National Academy of Sciences, USA, 101, 3490-3494.

Allendorf FW, Luikart G (2007) Conservation and the Genetics of Populations. Blackwell Publishing, Oxford, UK.

Allentoft ME, Oskam C, Houston J et al. (2011) Profiling the dead: generating microsatellite data from fossil bones of extinct megafauna - protocols, problems, and prospects. Public Library of Science ONE, 6, e16670.

Anderson EC, Williamson EG, Thompson EA (2000) Monte Carlo evaluation of the likelihood for $N($ e) from temporally spaced samples. Genetics, 156, 2109-2118.

Balloux F (2010) The worm in the fruit of the mitochondrial DNA tree. Heredity, 104, 419-420.

Barnes I, Matheus P, Shapiro B, Jensen D, Cooper A (2002) Dynamics of Pleistocene population extinctions in Beringian brown bears. Science, 295, 2267-2270.

Barnes I, Shapiro B, Lister A et al. (2007) Genetic structure and extinction of the woolly mammoth, Mammuthus primigenius. Current Biology, 17, 1072-1075.

Beaumont MA (2003) Estimation of population growth or decline in genetically monitored populations. Genetics, 164, 1139-1160.

Beaumont MA (2010) Approximate Bayesian computation in evolution and ecology. Annual Review of Ecology, Evolution and Systematics, 41, 379-406.

Beaumont MA, Zhang W, Balding DJ (2002) Approximate Bayesian computation in population genetics. Genetics, 162, 2025-2035.

Berthier P, Beaumont MA, Cornuet J-M, Luikart G (2002) Likelihood-based estimation of the effective population size using temporal changes in allele frequencies: a genealogical approach. Genetics, 160, 741-751.

Campos PF, Willerslev E, Sher A et al. (2010) Ancient DNA analyses exclude humans as the driving force behind late Pleistocene musk ox (Ovibos moschatus) population dynamics. Proceedings of the National Academy of Sciences, USA, 107, 5675-5680.
Colson IB, Bailey JF, Vercauteren M, Sykes BC, Hedges REM (1997) The preservation of ancient DNA and bone diagenesis. Ancient Biomolecules, 1, 109-117.

Comstock KE, Wasser SK, Ostrander EA (2000) Polymorphic microsatellite DNA loci identified in the African elephant (Loxodonta africana). Molecular Ecology, 9, 1004-1006.

Debruyne R, Chu G, King CE et al. (2008) Out of America: ancient DNA evidence for a New World origin of Late Quaternary woolly mammoths. Current Biology, 18, 1320-1326.

Depaulis F, Orlando L, Hänni C (2009) Using classical population genetics tools with heterochroneous data: time matters! Public Library of Science ONE, 4, e5541.

Eggert LS, Ramakrishnan U, Mundy NI, Woodruff DS (2000) Polymorphic microsatellite DNA markers in the African elephant (Loxondonta africana) and their use in the Asian elephant (Elephas maximus). Molecular Ecology, 9, 2223-2225.

Excoffier L, Lischer HEL (2010) Arlequin suite ver 3.5: a new series of programs to perform population genetics analyses under Linux and Windows. Molecular Ecology Resources, 10, 564-567.

Fairbanks RG (1989) A 17,000-year glacio-eustatic sea level record: influence of glacial melting rates on the younger dryas event and deep-ocean circulation. Nature, 342, 637-642.

Flagstad $\varnothing$, Walker CW, Vilà C et al. (2003) Two centuries of the Scandinavian wolf population: patterns of genetic variability and migration during an era of dramatic decline. Molecular Ecology, 12, 869-880.

Franklin IR, Frankham R (1998) How large must populations be to retain evolutionary potential? Animal Conservation, 1, 69-70.

Gagneux P, Boesch CW, Woodruff DS (1997) Microsatellite scoring errors associated with noninvasive genotyping based on nuclear DNA amplified from shed hair. Molecular Ecology, 6, 861-868.

Galtier N, Nabholz B, Glemin S, Hurst GDD (2009) Mitochondrial DNA as a marker of molecular diversity: a reappraisal. Molecular Ecology, 18, 4541-4550.

Gilbert MTP, Drautz DI, Lesk AM et al. (2008) Intraspecific phylogenetic analysis of Siberian woolly mammoths using complete mitochondrial genomes. Proceedings of the National Academy of Sciences, USA, 105, 8327-8332.

Hall TA (1999) BioEdit: a user-friendly biological sequence alignment editor and analysis program for Windows 95/98/NT. Nucleic Acids Symposium Series, 41, 95-98.

Hofreiter M, Serre D, Poinar HN, Kuch M, Pääbo S (2001) Ancient DNA. Nature Reviews Genetics, 2, 353-359.

Hofreiter M, Münzel S, Conard NJ et al. (2007) Sudden replacement of cave bear mitochondrial DNA in the late Pleistocene. Current Biology, 17, R122.

Jakobsson M (2009) COMPASS: a program for generating serial samples under an infinite sites model. Bioinformatics, 25, 2845-2847.

Jakobsson M, Rosenberg NA (2007) CLUMPP: a cluster matching and permutation program for dealing with label switching and multimodality in analysis of population structure. Bioinformatics, 23, 1801-1806.

Kongrit C, Siripunkaw C, Brockelman WY, Akkarapatumwong V, Wright TF, Eggert LS (2008) Isolation and characterization of dinucleotide microsatellite loci in the Asian elephant (Elephas maximus). Molecular Ecology Resources, 8, 175-177. 
Krimbas CB, Tsakas S (1971) The genetics of Dacus oleae. V. Changes of esterase polymorphism in a natural population following insecticide control - selection or drift? Evolution, 25, 454-460.

Lister AM, Sher AV (2001) The origin and evolution of the woolly mammoth. Science, 294, 1094-1097.

Lister AM, Stuart AJ (2008) The impact of climate change on large mammal distribution and extinction: evidence from the last glacial/interglacial transition. Comptes Rendus Geosciences, 340, 615-620.

Lister AM, Sher AV, van Essen H, Wei GB (2005) The pattern and process of mammoth evolution in Eurasia. Quaternary International, 126-128, 49-64.

Lorenzen ED, Nogues-Bravo D, Orlando L et al. (2011) Speciesspecific responses of Late Quaternary megafauna to climate and humans. Nature, 479, 359-364.

Morin PA, LeDuc RG, Archer FI et al. (2009) Significant deviations from Hardy-Weinberg equilibrium caused by low levels of microsatellite genotyping errors. Molecular Ecology Resources, 9, 498-504.

Nielsen R, Beaumont MA (2009) Statistical inferences in phylogeography. Molecular Ecology, 18, 1034-1047.

Nikolskiy PA, Sulerzhitsky LD, Pitulko VV (2011) Last straw versus Blitzkrieg overkill: climate-driven changes in the Arctic Siberian mammoth population and the Late Pleistocene extinction problem. Quaternary Science Reviews, 30, 2309-2328.

Nyakaana S, Arctander P (1998) Isolation and characterization of microsatellite loci in the African elephant, Loxodonta africana. Molecular Ecology, 7, 1436-1437.

Nyström V, Angerbjörn A, Dalén L (2006) Genetic consequences of a demographic bottleneck in the Scandinavian arctic fox. Oikos, 114, 84-94.

Nyström V, Dalén L, Vartanyan S, Lidén K, Ryman N, Angerbjörn A (2010) Temporal genetic change in the last remaining population of woolly mammoth. Proceedings of the Royal Society B: Biological Sciences, 277, 2331-2337.

Pääbo S (1989) Ancient DNA: extraction, characterization, molecular cloning and enzymatic amplification. Proceedings of the National Academy of Sciences, USA, 86, 1939-1943.

Patterson N, Price AL, Reich D (2006) Population structure and eigenanalysis. Public Library of Science Genetics, 2, e190.

Poinar HN, Hoss M, Bada JL, Pääbo S (1996) Amino acid racemization and the preservation of ancient DNA. Science, 272, 864-866.

Poinar HN, Schwarz C, Qi J et al. (2006) Metagenomics to paleogenomics: large-scale sequencing of mammoth DNA. Science, 311, 392-394.

Pritchard JK, Stephens M, Donnelly P (2000) Inference of population structure using multilocus genotype data. Genetics, 155, 945-959.

Prost S, Anderson CNK (2011) TempNet: a method to display statistical parsimony networks for heterochronous DNA sequence data. Methods in Ecology and Evolution, 2, 663-667.

R Development Core Team (2008) R: A Language and Environment for Statistical Computing. $\mathrm{R}$ Foundation for Statistical Computing, Vienna, Austria. ISBN 3-900051-07-0. http: / / www.R-project.org.

Rice WR (1989) Analyzing tables of statistical tests. Evolution, 43, 223-225.
Shapiro B, Drummond AJ, Rambaut A et al. (2004) Rise and fall of the Beringian steppe bison. Science, 306, 1561-1565.

Stuart AJ, Sulerzhitsky LD, Orlova LA, Kuzmin YV, Lister AM (2002) The latest woolly mammoths (Mammuthus primigenius Blumenbach) in Europe and Asia: a review of the current evidence. Quaternary Science Reviews, 21, 1559-1569.

Stuart AJ, Kosintsev PA, Higham TFG, Lister AM (2004) Pleistocene to Holocene extinction dynamics in giant deer and woolly mammoth. Nature, 431, 684-689.

Sukumar R (1989) The Asian Elephant: Ecology and Management. Cambridge University Press, Cambridge, UK.

Szpiech ZA, Jakobsson M, Rosenberg NA (2008) ADZE: a rarefaction approach for counting alleles private to combinations of populations. Bioinformatics, 24, 2498-2504.

Tavaré S, Balding DJ, Griffiths RC, Donnelly P (1997) Inferring coalescence times from DNA sequence data. Genetics, 145, 505-518.

Vartanyan SL, Garutt VE, Sher AV (1993) Holocene dwarf mammoths from Wrangel Island in the Siberian Arctic. Nature, 362, 337-340.

Vartanyan SL, Tikhonov AN, Orlova LA (2005) The dynamic of mammoth distribution in the last refugia in Beringia. In: 2nd World of Elephants Congress. Short Papers and Abstracts (eds Agenbroad LD, Symington RL), pp. 195-196. The Mammoth Site, Hot Springs, South Dakota.

Vartanyan SL, Arslanov KA, Karhu JA, Possnert G, Sulerzhitsky LD (2008) Collection of radiocarbon dates on the mammoths (Mammuthus primigenius) and other genera of Wrangel Island, northeast Siberia, Russia. Quaternary Research, 70, 51-59.

Veltre D, Yesner D, Crossen K, Graham R, Coltrain J (2004) Patterns of faunal extinction and paleoclimatic change from mid-Holocene mammoth and polar bear remains, Pribilof Islands, Alaska. Quaternary Research, 70, 40-50.

Wandeler P, Smith S, Morin PA, Pettifor A, Funk SM (2003) Patterns of nuclear DNA degeneration over time - a case study in historic teeth samples. Molecular Ecology, 12, 1087-1093.

Wang J (2001) A pseudo-likelihood method for estimating effective population size from temporally spaced samples. Genetic Research, 78, 243-257.

Waples RS (1989) A generalized approach for estimating effective population size from temporal changes in allele frequency. Genetics, 121, 379-391.

Weir BS (1996) Genetic Data Analysis II. Sinauer Associates, Inc., Sunderland, Massachusetts.

V.N. designed the project, performed DNA analyses, computed population-genetic statistics, carried out Bayesian clustering analyses and co-wrote the paper; J.H. optimized the genotyping and performed DNA analyses; P.S. designed, performed and wrote the text on the PC-analysis and the approximate Bayesian demographic analysis under supervision from M.J., who also computed population-genetic summary statistics; N.J.M. helped with the genotyping; S.V. contributed with material and data; P.W.S., K.L., I.B., A.A. and A.L. contributed with resources and information, and helped interpret the data; L.D. conceived and designed the project, performed DNA analyses, and co-wrote the paper. All authors discussed the results and contributed to the preparation of the manuscript. 


\section{Data accessibility}

Sequences for novel mtDNA haplotypes reported here have been deposited in GenBank under accession numbers JQ394825-JQ394837 (see Table 1 for details). Microsatellite genotypes are available as Table S6 (Supporting information).

\section{Supporting information}

Additional supporting information may be found in the online version of this article.

Data S1 Materials and methods.

Table S1 Microsatellite loci with repeat unit, primer sequence and size range in African and Asian elephants.

Table S2 Estimated probability $(P)$ of falsely accepting a homozygote, given the observed rate of allelic dropout $(K)$, after three replicates for each locus according to Gagneux et al. (1997).

Table S3 Estimated mean likelihoods of data and posterior probabilities for each cluster $(K=1-5)$ for (a) the complete data set and (b) where individuals containing missing data were excluded from the analyses.

Table S4 Genetic variation in each locus and time period, after excluding individuals containing missing data.
Table S5 The observed allele frequencies for each locus and time period.

Table S6 Microsatellite genotypes.

Fig. S1 Estimated population structure from analyses performed on individuals with complete genotypes $(n=44)$.

Fig. S2 Variability as a function of standardized sample size for samples from before (black) and after (grey) $12 \mathrm{ka}$.

Fig. S3 Posterior predictive simulations recapitulating the correlation between PC1 and time when the effective population size after $12 \mathrm{ka}$ is severely contracted. Samples $>12 \mathrm{ka}$ are shown as black squares and samples $<9$ ka are shown as grey circles. PC1 plotted against time is shown on top and PC1 vs. PC2 on bottom.

Fig. S4 Marginal posterior predictive distribution for each of 12 different summary statistics based on posterior parameter distributions obtained for the 2-epoch model.

Fig. S5 Marginal posterior predictive distribution for each of 12 different summary statistics based on posterior parameter distributions obtained for the 3-epoch model.

Please note: Wiley-Blackwell is not responsible for the content or functionality of any supporting information supplied by the authors. Any queries (other than missing material) should be directed to the corresponding author for the article. 